\title{
Phosphate flow in the chemotactic response system of Helicobacter pylori
}

\author{
María-Antonieta Jiménez-Pearson, ${ }^{1}$ Isabel Delany, ${ }^{2}$ Vincenzo Scarlato ${ }^{2}$ \\ and Dagmar Beier ${ }^{1}$
}

\begin{abstract}
Correspondence
Dagmar Beier

d.beier@biozentrum.

uni-wuerzburg.de
\end{abstract}

Received 24 May 2005

Revised 25 July 2005

Accepted 26 July 2005

\author{
${ }^{1}$ Theodor-Boveri-Institut für Biowissenschaften, Lehrstuhl für Mikrobiologie, Universität \\ Würzburg, Am Hubland, D-97074 Würzburg, Germany \\ ${ }^{2}$ Molecular Immunology Unit, Chiron Vaccines, Via Fiorentina 1, 53100 Siena, Italy
}

\section{INTRODUCTION}

Helicobacter pylori is the causative agent of chronic type B gastritis and gastric or duodenal ulcers (Blaser, 1992; Peterson, 1991). Moreover, infection with $H$. pylori increases the risk of developing gastric malignancies like adenocarcinoma or mucosa-associated lymphoid tissue (MALT) lymphoma (Uemura et al., 2001). Flagella-based motility is an important virulence trait of this pathogen since nonmotile mutants have been shown to be unable to colonize mice and piglets (Eaton et al., 1992, 1996; Ottemann \& Lowenthal, 2002). Accordingly it has been demonstrated that non-chemotactic mutants of $H$. pylori are attenuated in animal infection models (Ottemann \& Lowenthal, 2002; McGee et al., 2005; Terry et al., 2005).

Bacterial chemotaxis is a bias of movement towards beneficial or away from harmful chemicals. It has been reported that in vitro, $H$. pylori exhibits chemotaxis towards urea and various amino acids, while bile acids act as chemorepellents (Yoshiyama et al., 1999; Cerda et al., 2003; Worku et al., 2004). The biochemical processes governing chemotactic behaviour have been extensively studied in Escherichia coli (reviewed by Szurmant \& Ordal, 2004;

Abbreviation: MCP, methyl-accepting chemotaxis protein.
Wadhams \& Armitage, 2004). Briefly, binding of a ligand to the extracytoplasmic domain of a methyl-accepting chemotaxis protein (MCP) induces a conformational change of its cytoplasmic signalling domain which interacts with the adaptor protein $\mathrm{CheW}$ and the histidine kinase CheA. Changes in MCP conformation alter the autokinase activity of CheA and phosphorylated CheA transfers the phosphoryl group from the conserved histidine residue of its P1 domain to the response regulator $\mathrm{CheY}$. The phosphorylated $\mathrm{CheY}$ $(\mathrm{CheY} \sim \mathrm{P})$ interacts directly with the protein FliM in the flagellar motor switch complex to change the direction of flagellar rotation. The response is terminated by $\mathrm{CheZ}$ which accelerates the hydrolysis of $\mathrm{CheY} \sim \mathrm{P}$.

From the genome sequence, which contains nine orthologues to known chemotaxis genes (Alm et al., 1999; Tomb et al., 1997), it can be predicted that chemotactic signalling in $H$. pylori differs from the enterobacterial paradigm. $H$. pylori encodes three classical MCPs (HP0082, HP0099, HP0103), which are likely to sense ligands external to the cell, a soluble MCP orthologue (HP0599) which might respond to internal physiological signals, a coupling protein CheW (HP0391), a histidine kinase CheA containing a Cterminal CheY-like receiver domain (CheAY2/HP0392) and a separate CheY response regulator (CheY1/HP1067). Orthologues of the genes cheR encoding a methyltransferase 
and $c h e B$ encoding a response regulator with methylesterase activity are not present. In E. coli CheR and CheB are part of a stimulus-adaptation system which acts by modulating the ability of the MCPs to induce CheA autophosphorylation through the reversible methylation of glutamic acid residues in the cytoplasmic methylation region of the MCPs. Interestingly, the $H$. pylori MCPs contain several of the conserved glutamate residues of the methylation domain and the closely related organisms Helicobacter hepaticus, Campylobacter jejuni and Wolinella succinogenes encode orthologues of CheR and CheB; however, these CheB-like proteins do not contain a receiver domain (Parkhill et al., 2000; Baar et al., 2003; Suerbaum et al., 2003). H. pylori contains three orthologues of the $\mathrm{CheV}$ protein which was first described in Bacillus subtilis and was shown to be involved in the adaptation to attractants in this organism. $\mathrm{CheV}$ consists of an N-terminal CheW-like domain and a C-terminal receiver domain. Phosphorylation of the receiver domain of $\mathrm{CheV}$ is required for efficient adaptation (Karatan et al., 2001). Inactivation of cheV1 (HP0019) significantly reduced swarming of $H$. pylori on semi-solid agar plates, while swarming was unchanged in insertion mutants of cheV2 (HP0616) and cheV3 (HP0393), respectively, and in a cheV2/cheV3 double mutant (Pittman et al., 2001). Therefore, the mechanisms of adaptation adopted by $H$. pylori remain unclear.

An orthologue of the CheY $\sim \mathrm{P}$-specific phosphatase CheZ, which is involved in signal termination in $\beta$ - and $\gamma$ Proteobacteria, is missing in $H$. pylori. However, the presence of a CheY protein (CheY2) fused to the $\mathrm{C}$ terminus of the histidine kinase CheA as well as of a separate $\mathrm{CheY}$ response regulator (CheY1) is reminiscent of the chemotaxis system of Sinorhizobium meliloti. This organism encodes two separate CheY proteins which are both rapidly phosphorylated by CheA. However, only one CheY protein (CheY2) interacts with the flagellar motor when phosphorylated and, therefore, controls flagellar rotation directly, while the second CheY protein (CheY1) functions as a modulator of the chemotactic response by acting as a phosphate sink which drains away the phosphoryl group from $\mathrm{CheY} 2 \sim \mathrm{P}$ via retro-phosphorylation of the histidine kinase CheA. Since CheY1 is present in S. meliloti in a tenfold excess over CheA, retro-phosphorylation in the signal transduction chain is an efficient mechanism for dephosphorylation of CheY2 P (Schmitt, 2002).

Since virtually nothing is known about the molecular mechanisms controlling chemotaxis, which is an important virulence trait, in $H$. pylori, we purified the recombinant twocomponent chemotaxis proteins to investigate the phosphotransfer reactions between the different signalling modules in vitro. We show that $\mathrm{CheY} 1$, CheY2 and the three $\mathrm{CheV}$ proteins dephosphorylate CheA $\sim \mathrm{P}$ efficiently, but exhibit different affinities towards CheA. Furthermore, our data indicate that CheAY2 is retrophosphorylated by CheY1 P, suggesting a role of the C-terminal CheY2 domain of CheAY2 as a phosphate sink to modulate the half-life of CheY1 $\sim \mathrm{P}$.

\section{METHODS}

Bacterial strains and growth conditions. H. pylori G27 is a clinical isolate (Xiang et al., 1995) and was cultivated as described previously (Beier et al., 1997). Campylobacter jejuni 4344 is a clinical isolate which was obtained from the German Campylobacter and Helicobacter Reference Laboratory (Freiburg, Germany). The E. coli strains and plasmids used in this study are listed in Table 1. E. coli strains were grown in Luria-Bertani broth. When necessary antibiotics were added to the following final concentrations: ampicillin, $100 \mu \mathrm{g} \mathrm{ml}^{-1}$, and kanamycin, $25 \mu \mathrm{g} \mathrm{ml}^{-1}$.

Construction of plasmids expressing $\boldsymbol{H}$. pylori chemotaxis proteins fused to $\mathbf{H i s}_{\mathbf{6}}$ or GST affinity tags. Chromosomal DNA of $H$. pylori G27 was used as template DNA to PCR-amplify the $H$. pylori chemotaxis genes. The PCR primers used are listed in Table 2. All cloned PCR products were sequenced to ensure proper PCR amplification. The full-length cheA gene (HP0392/cheAY2) was amplified with primers cheF and cheR. The resulting PCR product which contains an internal NheI site was partially digested with NheI and BamHI and the $2412 \mathrm{bp}$ fragment was subsequently cloned into pTrcHisA vector DNA, generating pTrc-cheAY2. The truncated che $A^{\prime}$ allele encoding amino acids 1-667 of CheAY2 was amplified with primers cheF and $\mathrm{CA}^{\prime}-\mathrm{R}$, digested with NheI and BamHI and cloned into pTrcHisA to yield plasmid pTrc-cheA'. The cheY1 gene (HP1067) was amplified with primer pair cheY1-5/cheY1-3 and the resulting PCR fragment was cloned into pGEX-3X vector DNA after restriction with BamHI/EcoRI, generating pGEX-cheY1. The BamHI/ EcoRI cheY1 fragment was also cloned into pSL1180 vector DNA and the resulting plasmid was used as template for site-directed mutagenesis using the QuickChange Site-Directed Mutagenesis Kit (Stratagene), creating cheY1-D53N. The cheY1-D53N allele was subsequently cloned into pGEX-3X. To construct pTrc-cheY2 expressing the receiver domain of the bifunctional histidine kinase CheAY2, a 384 bp DNA fragment encoding amino acids 678-803 of CheAY2 was amplified with primers CARR-F and cheR and cloned into NheI- and BamHI-digested pTrcHisA vector DNA. The genes cheV1 (HP0019), cheV2 (HP0616) and cheV3 (HP0393) were amplified with primer pairs cheV1-5/cheV1-3, cheV2-5/cheV2-3 and cheV3-5/ cheV3-3, respectively, and the resulting PCR fragments were subsequently cloned into pQE30 vector DNA. The cheY1 orthologue of C. jejuni was amplified from chromosomal DNA of C. jejuni 4344 with primer pair CjcheY1-5/CjcheY1-3 and the resulting DNA fragment of $390 \mathrm{bp}$ was cloned into pGEX-3X vector DNA after digestion with BamHI and EcoRI, yielding plasmid pGEX-CjcheY1.

Expression and purification of fusion proteins. The $\mathrm{His}_{6^{-}}$and GST-fusion proteins derived from the pTrc and pGEX constructs, respectively, were produced in E. coli DH5 $\alpha$. pQE plasmids with inserts encoding $\mathrm{His}_{6}$-fusion proteins were propagated in E. coli M15. Expression and purification of GST- and $\mathrm{His}_{6}$-fusion proteins was performed as described previously (Perraud et al., 1998; Beier \& Frank, 2000).

In vitro phosphorylation assays. In vitro phosphorylation assays were carried out at $30^{\circ} \mathrm{C}$ in a final volume of $25 \mu \mathrm{l}$ reaction buffer (50 mM Tris/HCl, pH 7.5, $50 \mathrm{mM} \mathrm{KCl}, 10 \mathrm{mM} \mathrm{MgCl}_{2}, 0.2 \mathrm{mM}$ ATP) containing CheAY2 or $\mathrm{CheA}^{\prime}$ and, where appropriate, the respective response regulator proteins. The concentration of proteins and the reaction times applied are specified in the figure legends. Autophosphorylation of CheAY2 and CheA', as well as transphosphorylation of CheY1, CheY1-D53N, CheY2, CheV1, CheV2 and $\mathrm{CheV} 3$ in the presence of CheAY2 and $\mathrm{CheA}^{\prime}$, respectively, under multiple turnover conditions, was initiated by the addition of $50 \mathrm{nM}\left[\gamma_{-}{ }^{32} \mathrm{P}\right] \mathrm{ATP} \quad\left(5000 \mathrm{Ci} \mathrm{mmol}^{-1}\right)$. Phosphotransfer reactions from CheA' $\sim \mathrm{P}$ to CheY1, CheY1-D53N, CheY2, CheV1, CheV2 and $\mathrm{CheV} 3$, respectively, were initiated by the addition of the respective response regulator protein to $\mathrm{CheA}^{\prime}$ which had been incubated 
Table 1. Strains and plasmids

\begin{tabular}{|c|c|c|}
\hline Bacterial strain or plasmid & Relevant features & Reference or source \\
\hline \multicolumn{3}{|l|}{ Strains } \\
\hline H. pylori $\mathrm{G} 27$ & Clinical isolate & Xiang et al. (1995) \\
\hline C. jejuni 4344 & Clinical isolate & $\begin{array}{l}\text { German Reference Laboratory for } \\
\text { Helicobacter and Campylobacter, } \\
\text { Freiburg, Germany }\end{array}$ \\
\hline E. coli $\mathrm{DH} 5 \alpha$ & Strain used for high-efficiency transformation & Gibco \\
\hline E. coli M15 & Strain used for overproducing $\mathrm{His}_{6}$-tagged proteins & Qiagen \\
\hline \multicolumn{3}{|l|}{ Plasmids } \\
\hline pSL1180 & Cloning vector & Amersham Biosciences \\
\hline pTrcHisA & Expression vector for $\mathrm{N}$-terminal $\mathrm{His}_{6}$ tag cloning & Invitrogen \\
\hline pQE30 & Expression vector for $\mathrm{N}$-terminal $\mathrm{His}_{6}$ tag cloning & Qiagen \\
\hline pGEX-3X & GST gene fusion and expression vector & Amersham Biosciences \\
\hline pTrc-cheAY2 & pTrcHisA expressing the bifunctional CheAY2 protein of $H$. pylori & This study \\
\hline pTrc-cheA' & $\begin{array}{l}\text { pTrcHisA expressing a truncated derivative of CheAY2 comprising } \\
\text { amino acids } 1-676 \text { and lacking the C-terminal CheY2 domain }\end{array}$ & This study \\
\hline pGEX-cheY1 & pGEX-3X expressing CheY 1 of $H$. pylori & This study \\
\hline pSL-cheY1/D53N & $\begin{array}{l}\text { pSL1180 containing a } 373 \mathrm{bp} \mathrm{BamHI-EcoRI} \mathrm{fragment} \mathrm{encoding} \mathrm{a} \\
\text { mutated derivative of CheY1 of } H \text {. pylori with a D } 53 \mathrm{~N} \text { substitution }\end{array}$ & This study \\
\hline pGEX-cheY1/D53N & $\begin{array}{l}\text { pGEX-3X expressing a mutated derivative of } H \text {. pylori CheY1 with a } \\
\text { D53N substitution }\end{array}$ & This study \\
\hline pTrc-cheY2 & $\begin{array}{l}\text { pTrcHisA expressing the C-terminal CheY2 domain (amino acids } \\
677-803 \text { ) of the bifunctional CheAY2 protein of } H \text {. pylori }\end{array}$ & This study \\
\hline pQE-cheV1 & pQE30 expressing CheV1 of $H$. pylori & This study \\
\hline pQE-cheV2 & pQE30 expressing $\mathrm{CheV} 2$ of $H$. pylori & This study \\
\hline pQE-cheV3 & pQE30 expressing $\mathrm{CheV} 3$ of $H$. pylori & This study \\
\hline pGEX-CjcheY1 & pGEX-3X expressing CheY1 of C. jejuni & This study \\
\hline
\end{tabular}

Table 2. Oligonucleotides used in this study

\begin{tabular}{|c|c|c|c|c|}
\hline Name & Sequence $\left(5^{\prime}-3^{\prime}\right)^{*}$ & Site $\dagger$ & Strand & Position $\neq$ \\
\hline cheR & agcttggatccTCACGATTGGTCTCCTTCTAA & BamHI & + & $400546-400566$ \\
\hline CARR-F & attcaggctagcTATATTGTCTTAGCGATTGATG & NheI & - & $400908-400929$ \\
\hline cheY1-5 & catcacggatccGAAACTACTGGTAGTAGATGA & BamHI & + & $1126269-1126291$ \\
\hline cheY1-3 & tttcacgaattcTTAATCGTTTGTCCCTAAAACAACC & EcoRI & - & $1126620-1126642$ \\
\hline cheY1-D53N2 & GCATGTTCCAATTTGTAATAAGCAC & & - & $1126413-1126437$ \\
\hline cheV1-5 & catcacggatccGCTGATAGTTTAGCGGGCATTG & BamHI & + & $18377-18399$ \\
\hline cheV1-3 & tttcttggtaccTTATGCTAATTCCAAAAATTGCTTAAC & KpnI & - & $19321-19345$ \\
\hline cheV2-5 & catcacggatccGTAAGAGATATTGACAAAACGAC & Bam HI & + & $661114-661136$ \\
\hline cheV2-3 & tttcttctgcagTTATGAAAGCGTTTTTTTAAGCATTTC & Pst $\mathrm{I}$ & - & $662031-662058$ \\
\hline
\end{tabular}

*Sequences in upper-case letters are derived from the genome sequence of H. pylori 26695 (Tomb et al., 1997). Sequences introduced for cloning purposes are given in lower-case letters; restriction recognition sequences are underlined.

$\dagger$ Restriction recognition sites.

$\$$ Nucleotide positions refer to the genome sequence of H. pylori 26695 (Tomb et al., 1997) or C. jejuni (Parkhill et al., 2000) in the case of CjcheY1-5 and CjcheY1-3. 
for $15 \mathrm{~min}$ in the presence of $50 \mathrm{nM}\left[\gamma_{-}{ }^{32} \mathrm{P}\right] \mathrm{ATP}\left(5000 \mathrm{Ci} \mathrm{mmol}^{-1}\right)$ in reaction buffer. To determine the dephosphorylation rates of CheAY2 $\sim \mathrm{P}$ and $\mathrm{CheA}^{\prime} \sim \mathrm{P}$, either $2 \mu \mathrm{M}$ CheAY2 or $2 \mu \mathrm{M} \mathrm{CheA}^{\prime}$ were phosphorylated in the presence of $50 \mathrm{nM}\left[\gamma_{-}{ }^{32} \mathrm{P}\right] \mathrm{ATP}$ at $30^{\circ} \mathrm{C}$ for 10 and $15 \mathrm{~min}$, respectively. Subsequently, both reactions were chased by the addition of unlabelled ATP to a final concentration of $10 \mathrm{mM}$. To analyse the dephosphorylation rate of $\mathrm{CheY} 2$ in the presence of other chemotaxis response regulator proteins, $\mathrm{CheA}^{\prime}$ and CheY2 were incubated with $50 \mathrm{nM}\left[\gamma_{-}{ }^{32} \mathrm{P}\right] \mathrm{ATP}$ for $15 \mathrm{~min}$ at $30^{\circ} \mathrm{C}$. Then unlabelled ATP and/or the respective response regulator protein was added. The reactions were stopped at the indicated time points by the addition of sample buffer $(60 \mathrm{mM}$ Tris/HCl, pH 7.5, $50 \mathrm{mM} \mathrm{Na} \mathrm{EDTA}_{2} 10 \%$ glycerol, $2 \%$ SDS, $5 \%$ $\beta$-mercaptoethanol, $0.05 \%$ bromophenol blue) and the reaction mixtures were separated by electrophoresis on SDS- $15 \%$ polyacrylamide gels $(1.5 \mathrm{~mm})$. Quantification of the signals was performed using a Typhoon 9200 Variable Mode Imager (Amersham Biosciences) and ImageMaster TotalLab Software (Amersham Biosciences). All experiments were performed at least three times independently.

In vitro phosphorylation of the purified response regulator proteins with radioactively labelled acetyl phosphate was performed by incubating CheY1, CheY2, CheV1, CheV2 and CheV3, respectively, for $10 \mathrm{~min}$ at room temperature in a final volume of $25 \mu \mathrm{l}$ in reaction buffer ( $50 \mathrm{mM}$ Tris/ $\mathrm{HCl}, \mathrm{pH} 7 \cdot 5,50 \mathrm{mM} \mathrm{KCl}, 10 \mathrm{mM} \mathrm{MgCl}$ ) containing $5 \mu \mathrm{Ci}{ }^{32} \mathrm{P}$-labelled acetyl phosphate $\left(80 \mathrm{Ci} \mathrm{mmol}^{-1}\right.$; Hartmann Analytic). The dephosphorylation rates of CheY1 $\sim \mathrm{P}$ and CheY2 $\sim \mathrm{P}$ in the absence of $\mathrm{CheA}^{\prime}$ were determined by phosphorylating the response regulators in the presence of $5 \mu \mathrm{Ci}^{32} \mathrm{P}$-labelled acetyl phosphate $\left(80 \mathrm{Ci} \mathrm{mmol}^{-1}\right)$ for $10 \mathrm{~min}$ at room temperature and subsequently chasing the reactions by the addition of unlabelled acetyl phosphate to a final concentration of $10 \mathrm{mM}$. Retrophosphorylation experiments were performed in a final volume of $50 \mu \mathrm{l}$ reaction buffer in the presence of $5 \mu \mathrm{Ci}{ }^{32} \mathrm{P}$-labelled acetyl phosphate $\left(80 \mathrm{Ci} \mathrm{mmol}^{-1}\right)$. The analysis of samples and signal quantification was performed as described above.

\section{RESULTS}

\section{Purification of recombinant chemotaxis two- component proteins of $\boldsymbol{H}$. pylori and $\boldsymbol{C}$. jejuni}

The H. pylori chemotaxis genes cheAY2, cheY, cheV1, cheV2 and $c h e V 3$ were cloned into appropriate vectors creating $\mathrm{N}$ terminal fusions to a $\mathrm{His}_{6}$ or glutathione $S$-transferase affinity tag, allowing the overexpression of the recombinant proteins in E. coli and their purification by affinity chromatography. CheAY2, as well as a derivative of CheAY2 lacking the C-terminal CheY-like domain $\left(\mathrm{CheA}^{\prime}\right)$, were fused with an $\mathrm{N}$-terminal $\mathrm{His}_{6}$ affinity tag. In addition, a construct was established which expresses the C-terminal CheY-like domain of CheAY2 as a separate protein (CheY2) with an $\mathrm{N}$-terminal $\mathrm{His}_{6}$-tag. CheY1 and a derivative of CheY1 with a substitution of the putative phosphate-accepting aspartic acid residue at position 53 by asparagine (CheY1-D53N) were fused to glutathione $S$-transferase. The recombinant $\mathrm{CheV}$ proteins, $\mathrm{CheV1}$, CheV2 and $\mathrm{CheV} 3$, were overexpressed in $E$. coli with an $\mathrm{N}$-terminal $\mathrm{His}_{6}$-tag. Furthermore, the orthologous gene of cheY1 from C. jejuni (Cj118c) was cloned and was overexpressed with an $\mathrm{N}$-terminal glutathione $S$ transferase domain. A schematic representation of the purified recombinant proteins is shown in Fig. 1(a).

\section{Kinetics of autophosphorylation of CheAY2 and its C-terminally truncated derivative CheA'}

When CheAY2 and $\mathrm{CheA}^{\prime}$ were incubated in the presence of $\left[\gamma^{32} \mathrm{P}\right] \mathrm{ATP}$ autophosphorylation of the histidine kinases could be detected (Fig. 2). The ATP-dependent autophosphorylation of $\mathrm{CheA}^{\prime}$ followed a simple exponential time (a)

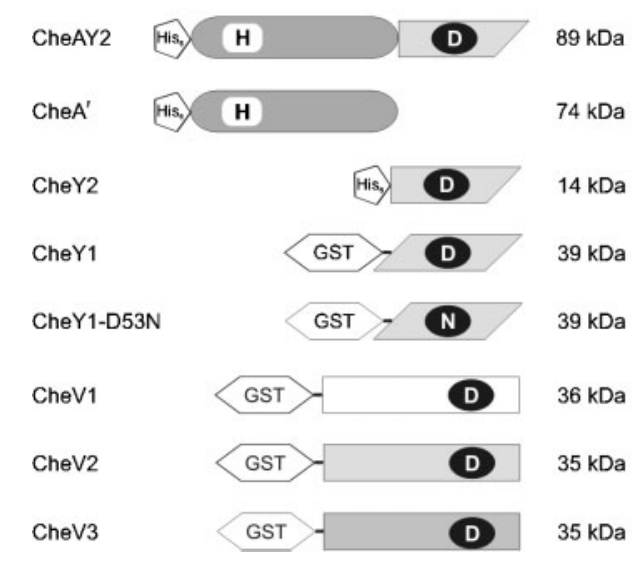

(b)

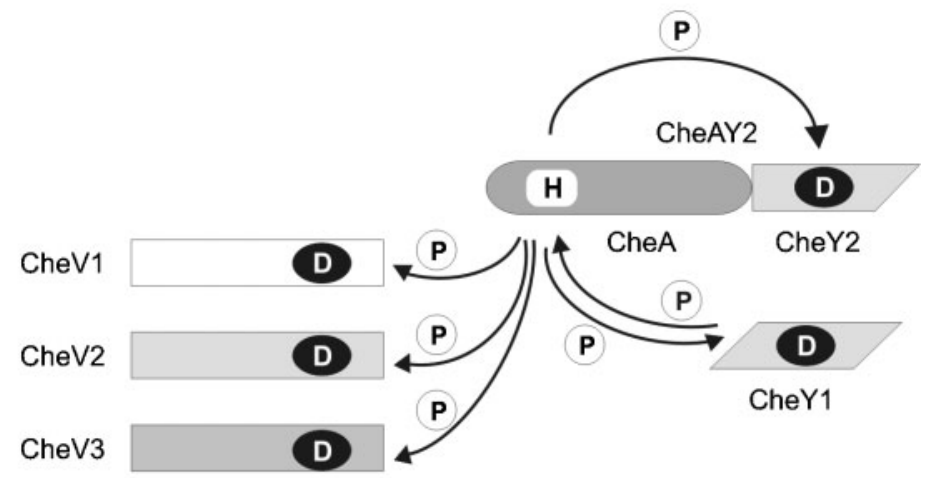

Fig. 1. Schematic representation of the chemotaxis two-component proteins of $H$. pylori. (a) Representation of the recombinant chemotaxis two-component proteins used in this study. The phosphorylated histidine residue in the P1 domain of the histidine kinase $(\mathrm{H})$ and the phosphate-accepting aspartic acid residues in the response regulator domains (D) are highlighted. The molecular masses of the proteins are given on the right. (b) Representation of the phosphotransfer reactions between the CheA histidine kinase and the chemotaxis response regulator proteins CheY1, CheY2 and CheV1-CheV3. Arrows indicate the direction of phosphorylation. 
(a)

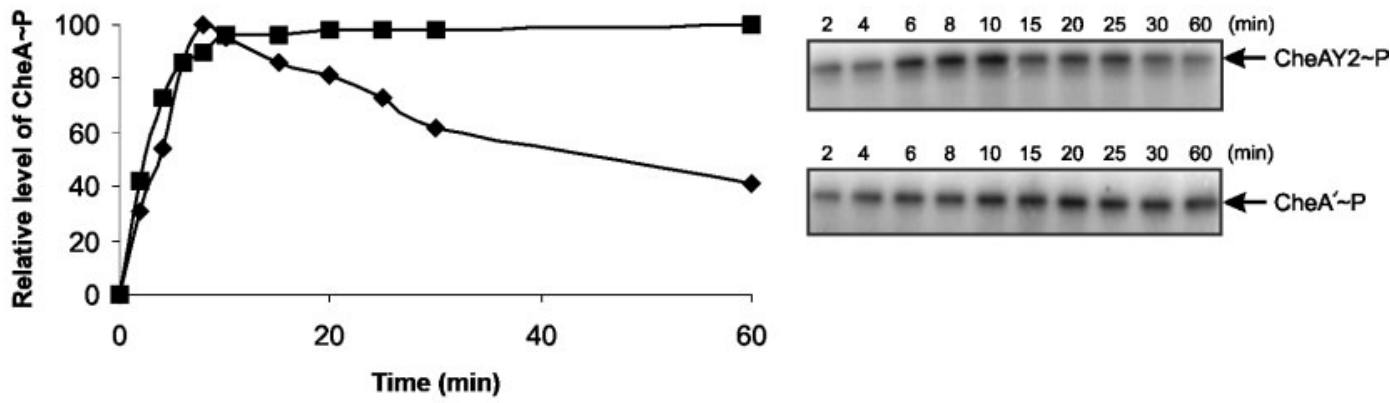

(b)

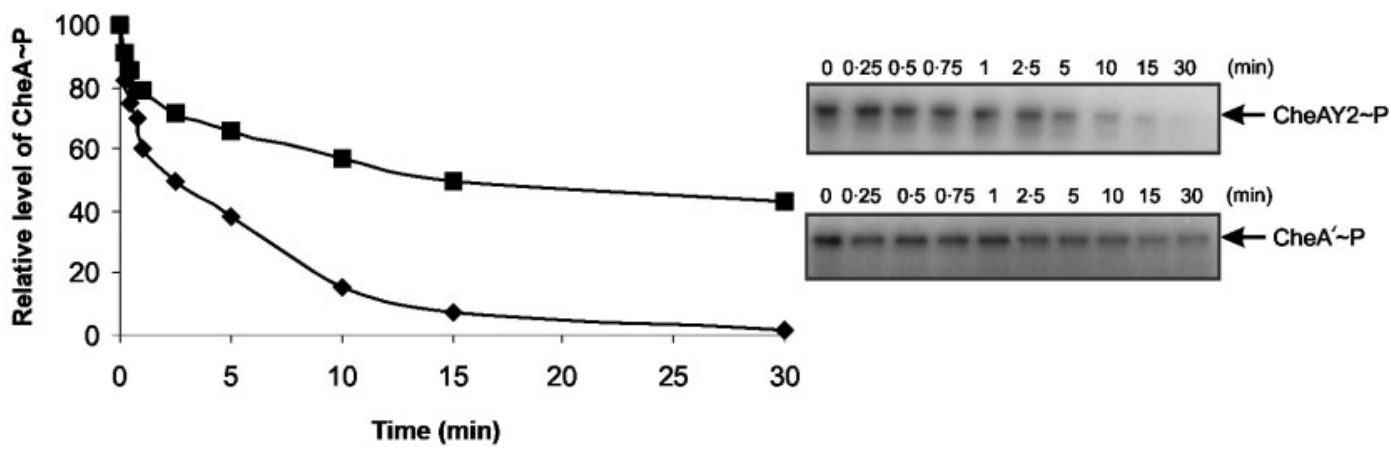

Fig. 2. Kinetics of ATP-dependent autophosphorylation of CheAY2 and $C h e A^{\prime}$ and dephosphorylation of CheAY2 $\sim P$ and $\mathrm{CheA}^{\prime} \sim \mathrm{P}$. (a) Time-course of CheAY2 $(\boldsymbol{)})$ and $\mathrm{CheA}^{\prime}(\boldsymbol{\square})$ autophosphorylation. Purified CheAY2 and CheA' (2 $\mu$ M each) were incubated in the presence of $50 \mathrm{nM}\left[\gamma^{-32} \mathrm{P}\right] \mathrm{ATP}$. At the indicated time points the reactions were stopped by the addition of sample buffer containing $50 \mathrm{mM} \mathrm{Na}{ }_{2}$ EDTA and the samples were analysed by SDS-PAGE. The relative amount of phosphorylated CheAY2 and CheA' was determined by Phosphor-Image analysis of the respective gels. The maximal phosphorylation level obtained for the respective histidine kinase was arbitrarily set as $100 \%$. Data points represent the means of three independent experiments. On the right phosphor images of representative SDS-15\% polyacrylamide gels are

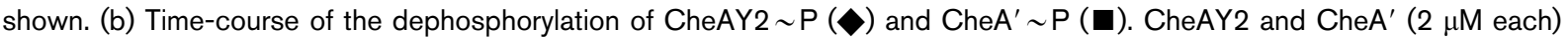
were incubated in the presence of $50 \mathrm{nM}\left[\gamma^{32} \mathrm{P}\right] \mathrm{ATP}$ for 10 and $15 \mathrm{~min}$, respectively. Then the reactions were chased by the addition of unlabelled ATP to a final concentration of $10 \mathrm{mM}$. At the indicated time points the reactions were stopped and the samples were analysed as described above. Data points represent the means of three independent experiments.

course, reaching the maximum level of phosphorylation of $\mathrm{CheA}^{\prime}$ after 15 min which remained constant for the rest of the incubation period ( $60 \mathrm{~min}$; Fig. 2a). In contrast, the full-length protein, CheAY2, reached the maximum level of phosphorylation after $8 \mathrm{~min}$ and then the relative level of CheAY2 $\sim \mathrm{P}$ continuously declined within $60 \mathrm{~min}$ of incubation to about $40 \%$ of the maximum level. This time course suggested that the C-terminal CheY-like domain of CheAY2 (CheY2) accelerates the dephosphorylation of the CheAY2 P1 domain containing the highly conserved histidine residue. To determine the half-life of CheAY2 $\sim \mathrm{P}$ and $\mathrm{CheA}^{\prime} \sim \mathrm{P}$, the phosphorylation reactions were chased after 10 and $15 \mathrm{~min}$, respectively, by the addition of an excess of unlabelled ATP. CheAY2 $\sim$ P hydrolysed with a half-life of $3 \mathrm{~min}$ and hydrolysis was almost complete after $15 \mathrm{~min}$ of chase (Fig. 2b). In the case of $\mathrm{CheA}^{\prime} \sim \mathrm{P}$, approximately $40 \%$ of the amount of phosphorylated $\mathrm{CheA}^{\prime}$ obtained after 15 min incubation with $\left[\gamma-{ }^{32} \mathrm{P}\right] \mathrm{ATP}$ could still be detected after $30 \mathrm{~min}$ of chase (Fig. 2b). When the phosphorylation reaction was chased for $60 \mathrm{~min}, 35 \%$ of the initial amount of $\mathrm{CheA}^{\prime} \sim \mathrm{P}$ remained detectable (data not shown). Therefore, the chase experiments corroborate the conclusion that the presence of $\mathrm{CheY} 2$ in the bifunctional CheAY2 protein significantly decreases the half-life of the phosphorylated histidine residue in the $\mathrm{P} 1$ domain of the CheA kinase.

\section{Che $A^{\prime}$-dependent phosphorylation of CheY2 and CheY1, and dephosphorylation of $\mathrm{CheA}^{\prime} \sim \mathrm{P}$ by the CheV proteins}

To study the phosphotransfer reactions from the CheA histidine kinase to the receiver modules involved in chemotactic signalling in $H$. pylori, CheAY2 and $\mathrm{CheA}^{\prime}$ were independently combined with the respective response regulator proteins in the presence of $\left[\gamma-{ }^{32} \mathrm{P}\right] \mathrm{ATP}$. Incubation of either CheAY2 or CheA' with CheY2 under multiple turnover conditions resulted in efficient phosphorylation of CheY2 (Fig. 3a, lanes 2 and 5, respectively). When the phosphotransfer to CheY1 was analysed under the same experimental conditions, dephosphorylation of the respective histidine kinase was observed; however, phosphorylated 


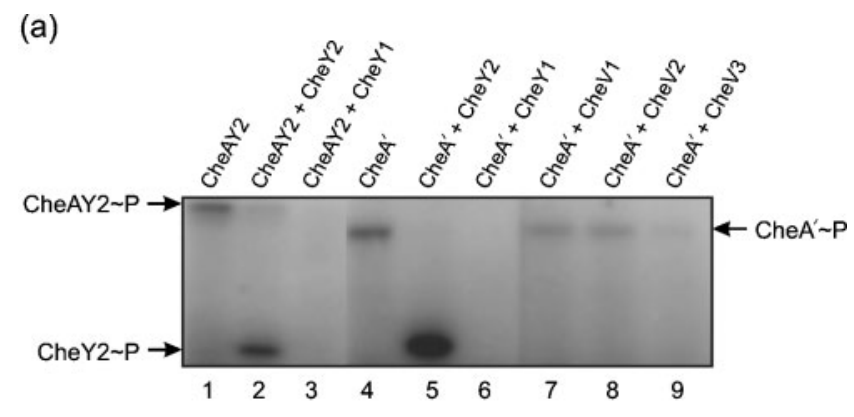

(b)

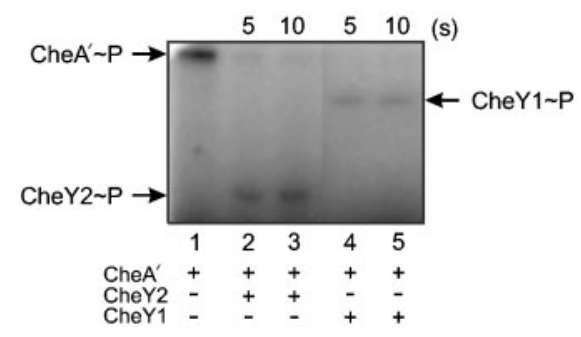

CheY1 did not accumulate (Fig. 3a, lanes 3 and 6, respectively). Dephosphorylation of $\mathrm{CheA}^{\prime} \sim \mathrm{P}$ did not occur when Che $\mathrm{A}^{\prime}$ and CheY1-D53N were combined in the presence of $\left[\gamma^{32} \mathrm{P}\right] \mathrm{ATP}$ (data not shown). These data indicated that the dephosphorylation of $\mathrm{CheA}^{\prime} \sim \mathrm{P}$ in the presence of $\mathrm{CheY} 1$ was due to the transfer of the phosphoryl group from the histidine kinase to D53 of CheY1. When CheY1 was added to a mixture of $\mathrm{CheA}^{\prime}$ and $\left[\gamma^{-}{ }^{32} \mathrm{P}\right] \mathrm{ATP}$ which had been preincubated for $15 \mathrm{~min}, \mathrm{CheY} 1 \sim \mathrm{P}$ could be detected within the first $10 \mathrm{~s}$ of incubation, but not at later time points (Fig. 3b). A similar fast phosphotransfer was observed upon addition of $\mathrm{CheY} 2$ to the reaction mixture (Fig. 3b). In the case of both CheY proteins, dephosphorylation of $\mathrm{CheA}^{\prime} \sim \mathrm{P}$ was complete $5 \mathrm{~s}$ after the addition of the response regulator protein. Neither CheY1
Fig. 3. Analysis of phosphoryl group transfer between the CheA histidine kinase and CheY1, CheY2 and the CheV proteins under multiple turnover conditions. (a) CheAY2 $(2 \mu \mathrm{M})$ was incubated in the presence of $\left[\gamma_{-}{ }^{32}\right.$ P]ATP (lane 1) and upon addition of $4 \mu \mathrm{M}$ CheY2 (lane 2) and $4 \mu \mathrm{M}$ CheY1, respectively, (lane 3) for $10 \mathrm{~min}$ at $30^{\circ} \mathrm{C}$. Similarly, CheA' $(2 \mu \mathrm{M})$ was incubated in the presence of $\left[\gamma^{32}\right.$ P]ATP (lane 4) and upon addition of $4 \mu \mathrm{M}$ CheY2 (lane 5), $4 \mu \mathrm{M}$ CheY1 (lane 6), $4 \mu \mathrm{M}$ CheV1 (lane 7), $4 \mu \mathrm{M}$ CheV2 (lane 8) and $4 \mu \mathrm{M}$ CheV3 (lane 9), respectively, for $15 \mathrm{~min}$ at $30^{\circ} \mathrm{C}$. The reactions were stopped by the addition of sample buffer containing $50 \mathrm{mM}$ $\mathrm{Na}_{2}$ EDTA. (b) CheA' $(2 \mu \mathrm{M})$ was phosphorylated in the presence of $\left[\gamma^{-32} \mathrm{P}\right] \mathrm{ATP}$ for $15 \mathrm{~min}$ (lane 1 ) and then $4 \mu \mathrm{M}$ CheY2 (lanes 2 and 3) and $4 \mu \mathrm{M}$ CheY1 (lanes 4 and 5), respectively, were added. After 5 (lanes 2 and 4) and $10 \mathrm{~s}$ (lanes 3 and 5) the reactions were stopped by the addition of sample buffer containing $50 \mathrm{mM} \mathrm{Na} \mathrm{mDDTA}_{2}$. The reaction mixtures were analysed by electrophoresis on a SDS-15\% polyacrylamide gel. Signal detection was performed by phosphorimaging.

nor CheY2 was phosphorylated in the presence of $\left[\gamma-{ }^{32} \mathrm{P}\right] \mathrm{ATP}$ alone (data not shown). Interestingly, the purified recombinant CheY protein of E. coli, which was used as a control, also caused the rapid dephosphorylation of $\mathrm{CheA}^{\prime} \sim \mathrm{P}$, but, as observed with CheY1 from H. pylori, $E$. coli $\mathrm{CheY} \sim \mathrm{P}$ did not accumulate under our experimental conditions (data not shown), while efficient phosphorylation of E. coli CheY by its cognate E. coli histidine kinase CheA has been reported under steady-state conditions (Bourret et al., 1990). When the CheV proteins were incubated in the presence of $\mathrm{CheA}^{\prime}$ and $\left[\gamma_{-}{ }^{32} \mathrm{P}\right] \mathrm{ATP}$ under multiple turnover conditions, moderate dephosphorylation of $\mathrm{CheA}^{\prime} \sim \mathrm{P}$ was observed in the case of $\mathrm{CheV} 1$ and $\mathrm{CheV} 2$, while $\mathrm{CheA}^{\prime} \sim \mathrm{P}$ was almost completely dephosphorylated in the presence of $\mathrm{CheV} 3$, indicating transfer of the phosphoryl group from $\mathrm{CheA}^{\prime}$ to the receiver domain of the $\mathrm{CheV}$ proteins. As in the case of $\mathrm{CheY} 1$, the phosphorylated

Fig. 4. $C h e A^{\prime}$-dependent phosphorylation of $C h e Y 2$ and dephosphorylation of $C h e Y 2 \sim P$ in the presence of other chemotaxis response regulator proteins. (a) CheA'-dependent phosphorylation of CheY2 in the presence of CheY1, CheY1D53N, CheV1, CheV2 and CheV3, respectively. Reaction mixtures containing $2 \mu \mathrm{M}$ CheA' (lane 1), $2 \mu \mathrm{M} C h e A^{\prime}$ and $4 \mu \mathrm{M}$ CheY2 (lanes 2 and 11), and $2 \mu \mathrm{M} \mathrm{CheA}^{\prime}, 4 \mu \mathrm{M}$ CheY2 and 1 or $4 \mu \mathrm{M}$ of the indicated response regulator protein (CheY1, lanes 3 and 4; CheY1-D53N, lanes 5 and 6; CheV3, lanes 7 and 8; CheV1, lanes 9 and 10; CheV2, lanes 12 and 13) were incubated in the presence of $\left[\gamma^{-32} \mathrm{P}\right]$ ATP for $15 \mathrm{~min}$. The reactions were stopped by the addition of sample buffer containing $50 \mathrm{mM} \mathrm{Na} \mathrm{NaDTA}_{2}$ and the reaction mixtures were analysed on an SDS-15\% polyacrylamide gel. (b) Kinetics of dephosphorylation of CheY2 $\sim \mathrm{P}$ alone $(\Delta)$ or in the presence of CheY1 $(\square)$, CheY1-D53N $(\bigcirc), \operatorname{CheV} 1(\triangle), \mathrm{CheV} 2(\times)$ and CheV3 $\left(^{*}\right)$. CheA ${ }^{\prime}$ and CheY2 $\left(2 \mu \mathrm{M}\right.$ each) were incubated in the presence of $\left[\gamma^{-}{ }^{32} \mathrm{P}\right] \mathrm{ATP}$ for 15 min. Then the respective response regulator protein was added to a final concentration of $2 \mu \mathrm{M}\left(t_{0}\right)$. At the indicated time points the reactions were stopped by the addition of sample buffer containing $50 \mathrm{mM} \mathrm{Na}{ }_{2}$ EDTA and the samples were analysed by SDS-PAGE. The relative amount of phosphorylated CheY2 was determined by phosphorimaging of the respective gels. The amount of phosphorylated CheY2 present after $15 \mathrm{~min}$ of incubation in the presence of CheA ${ }^{\prime}$ and $\left[\gamma^{-}{ }^{32} \mathrm{P}\right] \mathrm{ATP}$ and before the addition of the additional response regulator protein was arbitrarily set as $100 \%\left(t_{0}\right)$. Data points represent the means of three independent experiments. On the right, phosphorimages of representative SDS-15\% polyacrylamide gels are shown. (c) Kinetics of dephosphorylation of CheY2 $\sim \mathrm{P}$ in the presence of an excess of unlabelled ATP. CheA' and CheY2 $(2 \mu \mathrm{M}$ each) were incubated in the presence of $\left[\gamma^{-32}\right.$ P]ATP for $15 \mathrm{~min}$. Then unlabelled ATP $(\diamond$, final concn $10 \mathrm{mM})$ or both unlabelled ATP and CheY1 ( $\boldsymbol{\square}$, final concn $10 \mathrm{mM}$ and $2 \mu \mathrm{M}$, respectively) were added to the reaction mixture $\left(t_{0}\right)$. At the indicated time points the reactions were stopped and analysed by SDS-PAGE. Signal quantification was performed as described above. On the right, phosphorimages of representative SDS-15\% polyacrylamide gels are shown. 
CheV proteins could not be detected (Fig. 3a, lanes 7-9). Similar results were obtained when the phosphotransfer between CheAY2 and the CheV proteins was analysed under multiple turnover conditions (data not shown). When the CheV proteins were added to $\mathrm{CheA}^{\prime}$ which was autophosphorylated in the presence of $\left[\gamma^{32} \mathrm{P}\right] \mathrm{ATP}$ for $15 \mathrm{~min}$, complete dephosphorylation of $\mathrm{CheA}^{\prime} \sim \mathrm{P}$ was observed after $15 \mathrm{~s}$ incubation in the case of $\mathrm{CheV} 3$, while in the case of CheV1 and CheV2, 45 and $60 \%$, respectively, of the initial amount of $\mathrm{CheA}^{\prime} \sim \mathrm{P}$ was still detectable after $60 \mathrm{~s}$ incubation (data not shown). As observed for CheY1 and CheY2, the CheV proteins were not phosphorylated by $\left[\gamma^{32}-\mathrm{P}\right] \mathrm{ATP}$ (data not shown).

\section{CheY1, but not CheV1, CheV2 and CheV3, interferes with the Che $\mathrm{A}^{\prime}$-dependent phosphorylation of CheY2}

To study the effect of the various chemotaxis response regulator proteins on the $\mathrm{CheA}^{\prime}$-dependent phosphorylation of CheY2, CheA ${ }^{\prime}$ and CheY2 were incubated in the presence of $\left[\gamma^{32}\right.$-P]ATP and each of the response regulators independently under multiple turnover conditions. While the CheV proteins had no effect on the phosphorylation of CheY2 (compare Fig. 4a, lane 2 with lanes 7-10, and lane 11 with lanes 12-13), CheY2 $\sim \mathrm{P}$ could no longer be detected when CheY1 and CheY2 were present simultaneously in

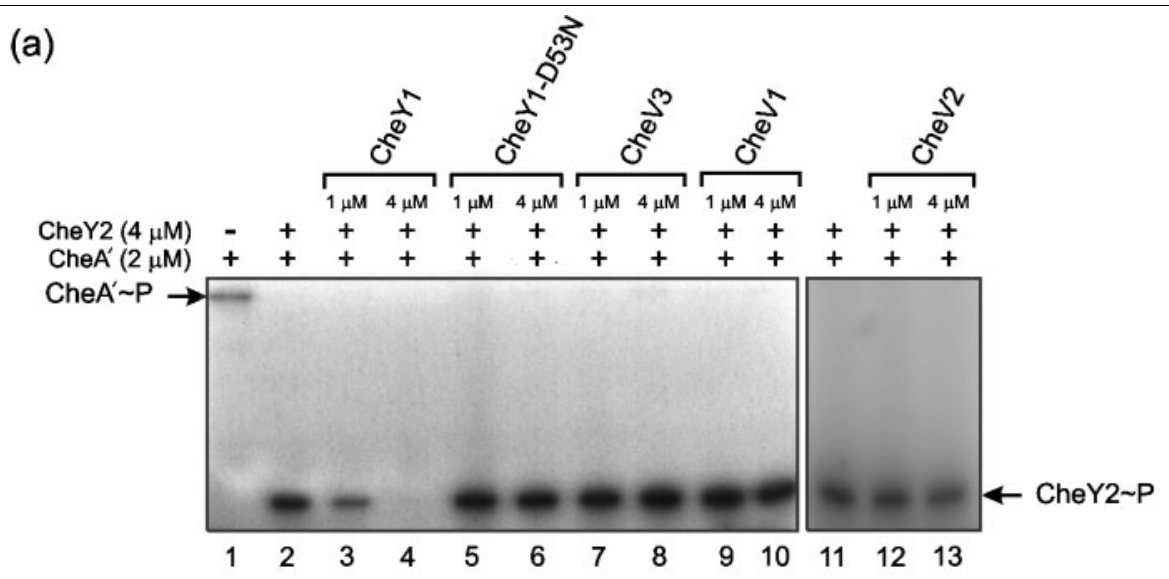

(b)

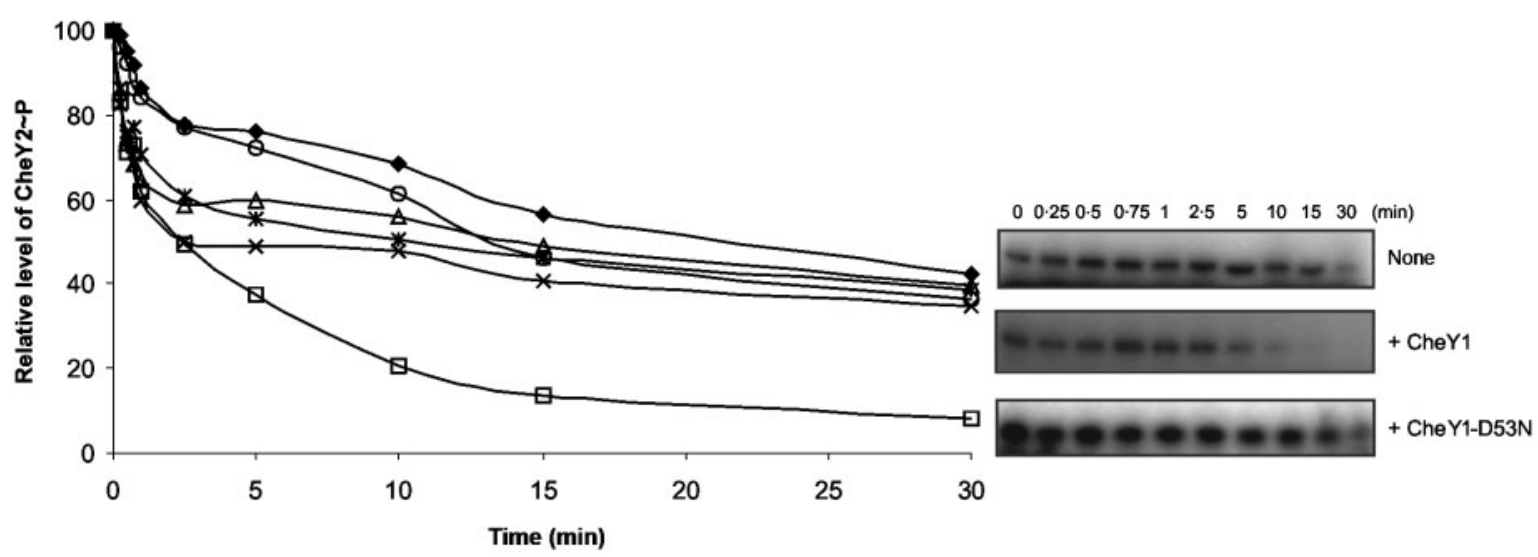

(c)
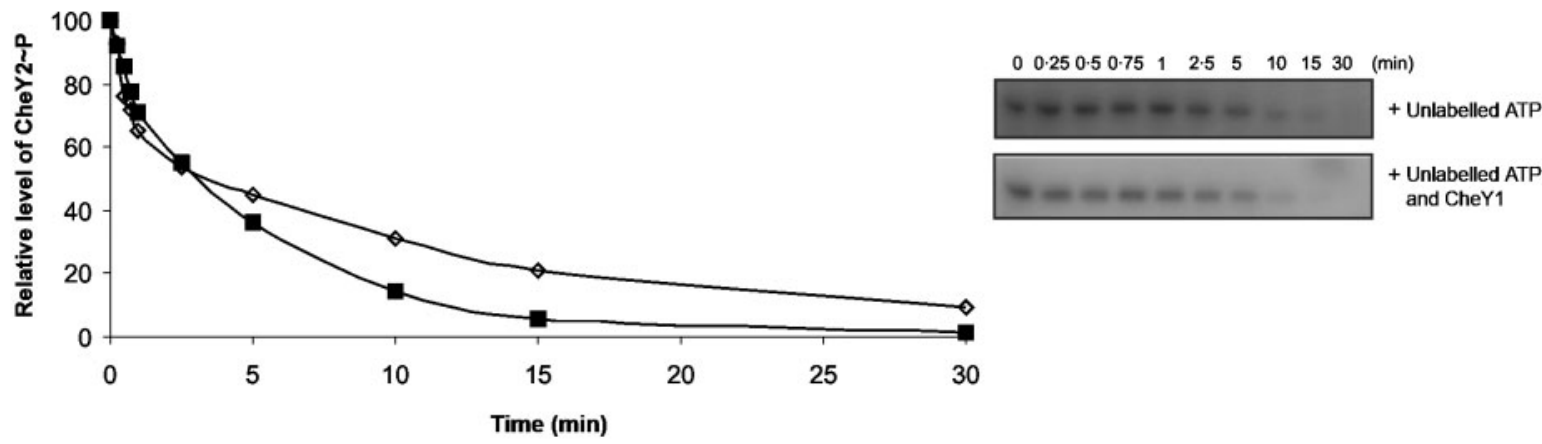
equimolar concentrations (compare Fig. 4a, lane 2 with lane 4). When CheY2 was present in the reaction mixture in a fourfold excess relative to CheY1, phosphorylation of CheY2 could be observed, but was clearly reduced as compared to the control reaction containing only CheY2 (compare Fig. 4a, lane 2 with lane 3). When the recombinant CheY1-D53N protein lacking the highly conserved phosphate-accepting aspartic acid residue was added to the reaction, no effect on the phosphorylation of CheY2 was observed (Fig. 4a, lanes 5 and 6). These results suggested that CheY1 strongly prevails over CheY2 in competition for the phosphoryl group donor $\mathrm{CheA}^{\prime} \sim \mathrm{P}$.

Next we analysed the effect of the chemotaxis response regulator proteins on $\mathrm{CheY} 2 \sim \mathrm{P}$ which was generated by preincubation with $\mathrm{CheA}^{\prime}$ in the presence of $\left[\gamma^{32}\right.$-P]ATP for 15 min. When CheY1 was added to the reaction mixture containing $\mathrm{CheA}^{\prime}, \mathrm{CheY} 2$ and $\left[\gamma^{32}\right.$-P]ATP, the relative amount of CheY2 $\sim \mathrm{P}$ declined rapidly and within $30 \mathrm{~min}$ of incubation to about $10 \%$ of the initial amount observed when CheY1 was added $\left(t_{0}\right)$. In contrast, about $45 \%$ of the amount of CheY2 $\sim \mathrm{P}$ present at $t_{0}$ remained detectable after 30 min when the decay of $\mathrm{CheY} 2 \sim \mathrm{P}$ was analysed in the absence of an additional response regulator protein (Fig. 4b). As expected from the results presented in Fig. 4(a), CheY1D53N had no effect on the decay of CheY2 $\sim \mathrm{P}$ in the timecourse experiment. A similar kinetic curve as monitored in the presence of CheY1 was also obtained when the heterologous recombinant CheY1 protein from $C$. jejuni was used, indicating a productive interaction of $H$. pylori $\mathrm{CheA}^{\prime}$ with this response regulator (data not shown). Addition of the $\mathrm{CheV}$ proteins somewhat reduced the amount of $\mathrm{CheY} 2 \sim \mathrm{P}$ within the first $15 \mathrm{~min}$ of incubation; however, the relative amount of $\mathrm{CheY} 2 \sim \mathrm{P}$ still present after $30 \mathrm{~min}$ was almost unchanged as compared to the reaction containing no additional response regulator protein.

We then performed a chase experiment to measure the decay of $\mathrm{CheY} 2 \sim \mathrm{P}$ in the absence of multiple phosphorylation turnover. When an excess of unlabelled ATP was added to $\mathrm{CheA}^{\prime}$ and CheY2 which were preincubated in the presence of $\left[\gamma^{32}\right.$-P]ATP for $15 \mathrm{~min}$, the kinetics of CheY2 $\sim \mathrm{P}$ hydrolysis was very similar to the time course obtained after addition of CheY1 to the reaction mixture (compare Fig. $4 \mathrm{~b}$ and $4 \mathrm{c}$ ). Under these experimental conditions the half-life of $\mathrm{CheY} 2 \sim \mathrm{P}$ was determined to be $3.3 \mathrm{~min}$. The simultaneous addition of CheY1 and unlabelled ATP had no pronounced effect on the half-life of CheY $2 \sim \mathrm{P}(3.0 \mathrm{~min}$; Fig. 4c). The difference in the kinetics of dephosphorylation of CheY2 $\sim \mathrm{P}$ observed in the absence or presence of an excess of unlabelled ATP indicated that, in the unchased reaction, phosphorylation of $\mathrm{CheA}^{\prime}$ and phosphotransfer to CheY2 continuously occurred in the investigated time period, resulting in the presence of a higher relative amount of CheY2 $\sim \mathrm{P}$ after 30 min incubation. It should be noted that $\mathrm{CheA}^{\prime} \sim \mathrm{P}$ was hardly detectable in the time-course experiments (data not shown). Therefore, we conclude that the effect on the half-life of $\mathrm{CheY} 2 \sim \mathrm{P}$ observed after addition of CheY1 to a mixture of $\mathrm{CheA}^{\prime}$ and $\mathrm{CheY} 2$ in the presence of $\left[\gamma^{32}\right.$-P]ATP is due to the almost exclusive phosphorylation of CheY1 by newly formed $\mathrm{CheA}^{\prime} \sim \mathrm{P}$ as a consequence of a more efficient interaction with $\mathrm{CheA}^{\prime} \sim \mathrm{P}$. Consequently, the prevalence of CheY1 in the competition for the phosphoryl group donor $\mathrm{CheA}^{\prime} \sim \mathrm{P}$ almost completely blocks any further phosphorylation of CheY2. These data suggest that CheY1 interacts more efficiently with $\mathrm{CheA}^{\prime} \sim \mathrm{P}$, possibly through a higher affinity for the histidine kinase than CheY2. This is also supported by the observation that CheY1 caused the complete dephosphorylation of $\mathrm{CheA}^{\prime} \sim \mathrm{P}$ within $10 \mathrm{~s}$ at $0{ }^{\circ} \mathrm{C}$ when it was added to Che $\mathrm{A}^{\prime}$ phosphorylated with $\left[\gamma^{32}\right.$-P]ATP for $15 \mathrm{~min}$, while about $20 \%$ of the initial amount of $\mathrm{CheA}^{\prime} \sim \mathrm{P}$ was still detectable when CheY2 was investigated under the same experimental conditions (data not shown).

\section{Phosphorylation of CheY1 and CheY2 by acetyl phosphate and retrophosphorylation of CheAY2 by CheY1 P}

Several response regulator proteins including $\mathrm{CheY}$ of $E$. coli are phosphorylated in vitro in the presence of lowmolecular-mass phosphate donors like acetyl phosphate (McCleary \& Stock, 1994; Lukat et al., 1992). When the recombinant $\mathrm{CheY} 1$ and $\mathrm{CheY} 2$ proteins of $H$. pylori were incubated with ${ }^{32} \mathrm{P}$-labelled acetyl phosphate, phosphorylation of both response regulators was observed (Fig. 5).

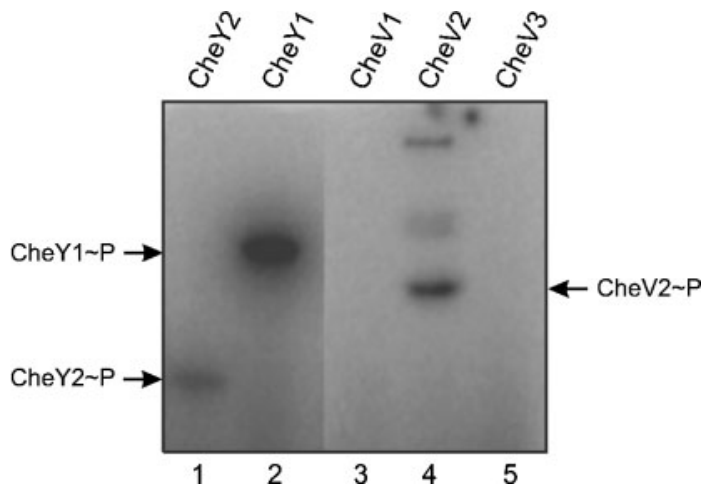

Fig. 5. Phosphorylation of CheY1, CheY2 and the CheV proteins by acetyl phosphate. CheY2 $(24 \mu \mathrm{M}$, lane 1), CheY1 (7 $\mu \mathrm{M}$, lane 2), CheV1 (4 $\mu \mathrm{M}$, lane 3), CheV2 (20 $\mu \mathrm{M}$, lane 4) and $\mathrm{CheV}_{3}(6 \mu \mathrm{M}$, lane 5$)$ were incubated in the presence of $5 \mu \mathrm{Ci}{ }^{32} \mathrm{P}$-labelled acetyl phosphate for $10 \mathrm{~min}$. The reactions were stopped by the addition of sample buffer containing $50 \mathrm{mM} \mathrm{Na}{ }_{2}$ EDTA, and the reaction mixtures were analysed by electrophoresis on a SDS-15\% polyacrylamide gel. Interestingly, phosphorylation signals from proteins of higher molecular mass than the monomeric CheV2 could also be detected which might suggest phosphorylation-induced oligomerization of CheV2, since contaminating proteins of similar sizes could not be detected in significant amounts when the purified CheV2 was analysed by SDS-PAGE and Coomassie staining (data not shown). 
However, the efficiency of in vitro phosphorylation differed significantly since CheY2 had to be present at a concentration of $24 \mu \mathrm{M}$ to detect CheY2 $\sim \mathrm{P}$ (Fig. 5, lane 1), while a strong phosphorylation signal was obtained when CheY1 was included in the reaction mixture at a concentration of $7 \mu \mathrm{M}$ (Fig. 5, lane 2). In vitro phosphorylation of $\mathrm{CheV} 2$ by acetyl phosphate could also be detected (Fig. 5, lane 4), while $\mathrm{CheV} 1$ and $\mathrm{CheV} 3$ were not phosphorylated under these conditions (Fig. 5, lanes 3 and 5, respectively). However, the presence of rather low concentrations of $\mathrm{CheV} 1$ and $\mathrm{CheV} 3$ in the reaction mixtures, which was due to the lower solubility of the recombinant proteins, might account for the lack of detectable phosphorylation. Chase experiments with unlabelled acetyl phosphate revealed that CheY1 $\sim \mathrm{P}$ was hydrolysed completely within $30 \mathrm{~min}$ of incubation, displaying a half-life of $20 \mathrm{~s}$. In contrast, CheY2 $\sim \mathrm{P}$ exhibited increased stability under these conditions since about $55 \%$ of the initial amount of CheY $2 \sim \mathrm{P}$ was still detectable after a 30 min chase (data not shown). As expected, the CheY-D53N protein could not be phosphorylated when incubated with ${ }^{32} \mathrm{P}$-labelled acetyl phosphate (data not shown), suggesting the phosphorylation of the response regulators on the conserved aspartic acid residue by the low-molecular-mass phosphate donor molecule.

To investigate whether retrotransfer of the phosphoryl group from one of the $\mathrm{CheY}$ proteins to the conserved histidine residue in the $\mathrm{P} 1$ domain of CheA is occurring in the chemotaxis system of $H$. pylori, we incubated either CheY1 or CheY2 in the presence of ${ }^{32} \mathrm{P}$-labelled acetyl phosphate and the CheA histidine kinase. When the truncated protein $\mathrm{CheA}^{\prime}$ was included in the reaction mixture, phosphorylated $\mathrm{CheA}^{\prime}$ could not be detected (data not shown). However, when CheAY2 was combined with CheY1, phosphorylation of the bifunctional protein was observed, while at the same time CheY1 $\sim \mathrm{P}$ was hydrolysed, suggesting retrotransfer of the phosphoryl group to CheAY2 (Fig. 6a, lane 2). CheY2 $\sim \mathrm{P}$ was not significantly hydrolysed in the presence of CheAY2 and phosphorylation of CheAY2 could not be detected (Fig. 6a, lane 4). As a control CheAY2 and $\mathrm{CheA}^{\prime}$ were incubated with ${ }^{32} \mathrm{P}$-labelled acetyl phosphate at the same protein concentration as used in the retrophosphorylation experiments. As expected, no phosphorylation of the histidine kinases was observed (Fig. 6a, lane 5 and Fig. 6b, lane 1). Although in vitro phosphorylation of the C-terminal receiver module of CheAY2 by acetyl phosphate could in principle occur, due to the low efficiency of phosphorylation exhibited by the separated CheY2 module CheAY2 was apparently present at too low a concentration to create a detectable signal.

Since retrophosphorylation from $\mathrm{CheY} 1 \sim \mathrm{P}$ should primarily target the histidine residue in the $\mathrm{P} 1$ domain of CheAY2, we investigated the effect of the truncated $\mathrm{CheA}^{\prime}$ protein on the phosphorylation state of the CheY proteins when the three chemotaxis proteins were present simultaneously. Incubation of a mixture of $\mathrm{CheY} 1$ and CheY2 with ${ }^{32} \mathrm{P}$-labelled acetyl phosphate resulted in the (a)

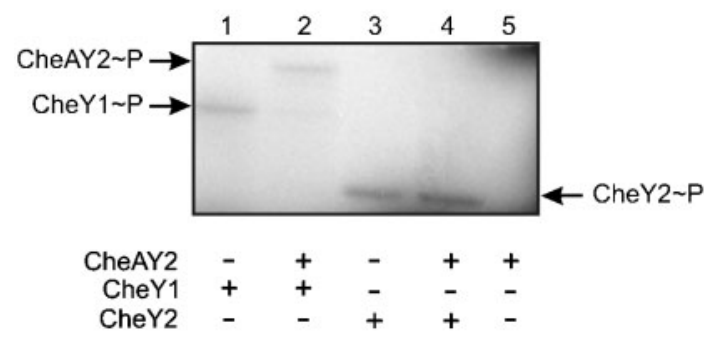

(b)

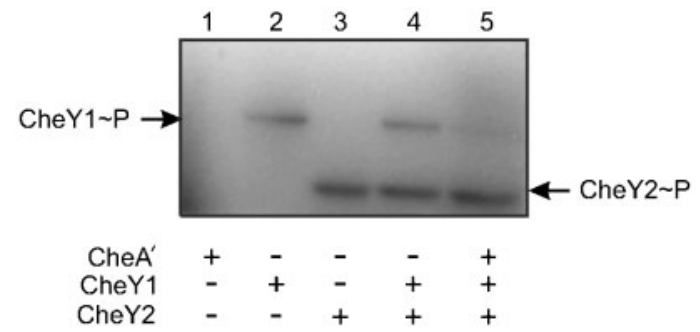

(c)

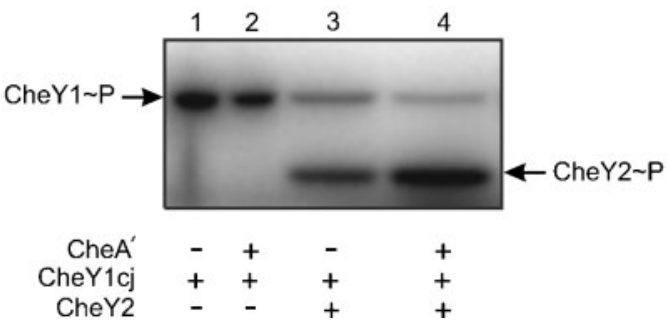

Fig. 6. Phosphorylation of CheY1 and CheY2 by acetyl phosphate in the presence of the histidine kinases CheAY2 and CheA'. (a) Retrophosphorylation of CheAY2 by CheY1 P. CheY1 $(7 \mu \mathrm{M}$, lanes 1 and 2$)$ or CheY2 $(50 \mu \mathrm{M}$, lanes 3 and 4) were incubated for $10 \mathrm{~min}$ with ${ }^{32} \mathrm{P}$-labelled acetyl phosphate in the absence (lanes 1 and 3 ) or presence (lanes 2 and 4) of $8 \mu \mathrm{M}$ CheAY2. As a control, $13 \mu \mathrm{M}$ CheAY2 was incubated with ${ }^{32} \mathrm{P}$-labelled acetyl phosphate (lane 5). (b) Phosphotransfer from CheY1 $\sim \mathrm{P}$ to CheY2 via CheA'. CheY1 (7 $\mu \mathrm{M}$, lane 2), CheY2 (50 $\mu \mathrm{M}$, lane 3$)$ and a mixture of either $7 \mu \mathrm{M}$ CheY1 and $50 \mu \mathrm{M}$ CheY2 (lane 4) or $7 \mu \mathrm{M}$ CheY1,

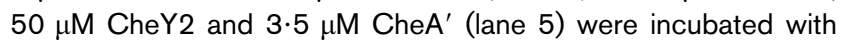
${ }^{32} \mathrm{P}$-labelled acetyl phosphate. As a control, 3.5 $\mu \mathrm{M} \mathrm{CheA}^{\prime}$ was also incubated with ${ }^{32} \mathrm{P}$-labelled acetyl phosphate (lane 1). (c) Phosphotransfer from CheY1 P of C. jejuni to CheY2 via CheA'. Purified recombinant CheY1cj $(7 \mu \mathrm{M})$ was incubated with ${ }^{32} \mathrm{P}$-labelled acetyl phosphate (lane 1) in the presence of

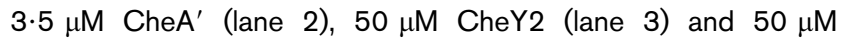

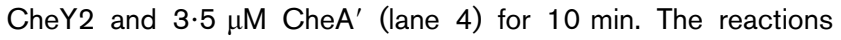
were stopped by the addition of sample buffer containing $50 \mathrm{mM} \mathrm{Na} \mathrm{N}_{2}$ EDTA and the reaction mixtures were analysed by electrophoresis on an SDS-15\% polyacrylamide gel. 
phosphorylation of both CheY proteins (Fig. 6b, lane 4). When $\mathrm{CheA}^{\prime}$ was included in the reaction mixture, the amount of $\mathrm{CheY} 1 \sim \mathrm{P}$ was clearly reduced while the amount of $\mathrm{CheY} 2 \sim \mathrm{P}$ increased, suggesting retrophosphorylation of CheA' by $\mathrm{CheY} 1 \sim \mathrm{P}$ and the subsequent phosphorylation of CheY2 by $\mathrm{CheA}^{\prime} \sim \mathrm{P}$ (Fig. $6 \mathrm{~b}$, lane 5 ). The same result was obtained when CheY1 was replaced by the recombinant orthologous protein from C. jejuni (Fig. 6c). However, in both experiments phosphorylated $\mathrm{CheA}^{\prime}$ could not be detected directly. From these experiments we conclude that phosphorylated CheY1 is able to efficiently transfer the phosphoryl group back to the CheAY2 histidine kinase, whereas efficient phosphotransfer from CheY2 $\sim \mathrm{P}$ to the P1 domain of CheAY2 does not occur. A summary of the phosphotransfer model based on the results of these experiments is shown in Fig. 1(b).

\section{DISCUSSION}

The chemotaxis system of $H$. pylori contains multiple signal transduction proteins which interact in a complex way. The chemotaxis histidine kinase CheAY2 is a bifunctional protein containing also a C-terminal CheY-like receiver domain. Such bifunctional CheAY proteins are also present in the other members of the $\varepsilon$-Proteobacteria whose genomes have been sequenced so far (Parkhill et al., 2000; Baar et al., 2003; Suerbaum et al., 2003). To investigate the phosphotransfer reactions between the CheA histidine kinase and the various chemotaxis response regulator proteins of $H$. pylori, we constructed two derivatives of CheAY2, one lacking the C-terminal CheY2 domain $\left(\mathrm{CheA}^{\prime}\right)$, the other comprising the separate CheY2 receiver domain (Fig. 1a). We have shown that the $\mathrm{N}$-terminal CheA domain of the histidine kinase protein can be autophosphorylated, presumably on the histidine of the P1 domain, and that the presence of the CheY2 receiver domain influences the stability of the phosphorylated bifunctional protein (Fig. 2). The reduced stability of CheAY2 $\sim \mathrm{P}$ compared to $\mathrm{CheA}^{\prime} \sim \mathrm{P}$ is probably due to an intramolecular phosphoryl group transfer from the histidine residue in the P1 domain to the phosphate-accepting aspartic acid residue in the C-terminal CheY2 domain and the subsequent rapid hydrolysis of CheY2 $\sim \mathrm{P}$. In accordance with this conclusion, rapid dephosphorylation of $\mathrm{CheA}^{\prime} \sim \mathrm{P}$ was also observed when the separated CheY2 domain was added (Fig. 3b). A similar effect of the receiver domain on the autophosphorylation kinetics of an unorthodox histidine kinase has been reported for the redox sensor ArcB of E. coli which is composed of a kinase domain, a receiver module and a Cterminal Hpt-domain (Georgellis et al., 1997). Because in chase experiments the phosphorylated CheY2 protein exhibited a higher stability in the absence of $\mathrm{CheA}^{\prime}$ than in its presence (data not shown and Fig. 4c), we hypothesize that the interaction with the $\mathrm{CheA}^{\prime}$ histidine kinase stimulates the hydrolysis of $\mathrm{CheY} 2 \sim \mathrm{P}$. This effect might be even more pronounced in an intramolecular interaction in the bifunctional CheAY2 protein.
Both CheY1 and CheY2 caused the efficient dephosphorylation of CheAY2 $\sim \mathrm{P}$ and $\mathrm{CheA}^{\prime} \sim \mathrm{P}$ (Fig. 3), while the phosphorylation state of the $H$. pylori histidine kinases HP244 and HP165 used as a control was unaffected by the addition of the chemotaxis response regulators (data not shown), demonstrating that CheAY2 constitutes the cognate histidine kinase for both CheY1 and CheY2. Unexpectedly, phosphorylated CheY1 did not accumulate in multiple turnover phosphotransfer reactions with CheAY2 or CheA', but this may possibly be explained by a relatively slow autophosphorylation of CheA in vitro when compared to the comparatively rapid hydrolysis of $\mathrm{CheY} 1 \sim \mathrm{P}$. For the intrinsic dephosphorylation of CheY1 $\sim \mathrm{P}$ a half-life of $20 \mathrm{~s}$ was determined, which is in the same range as the half-life of $\mathrm{CheY} \sim \mathrm{P}$ from E. coli (Lukat et al., 1991) but approximately twice as long as the half-lives of CheY1 and CheY2 from S. meliloti (Sourjik \& Schmitt, 1998). As was observed with the CheY proteins of S. meliloti (Sourjik \& Schmitt, 1998), CheY1 and CheY2 of $H$. pylori did not exhibit phosphatase activity towards each other (Fig. 6b). The results of three component phosphorylation assays suggested clearly that CheY1 prevails in the competition for $\mathrm{CheA}^{\prime} \sim \mathrm{P}$ over CheY2 (Fig. 4) and we interpret this as a higher affinity of CheY1 for $\mathrm{CheA}^{\prime}$; however, it is possible that the intramolecular phosphotransfer reaction within the bifunctional CheAY2 protein may be favoured in vivo.

In $H$. pylori no homologues of proteins with a known CheY $\sim$ P-specific phosphatase activity like CheZ, CheC and CheX are present. CheC was identified in B. subtilis and works in concert with another chemotaxis protein CheD (Szurmant et al., 2004). So far only the function of CheX from Thermotoga maritima was analysed in some detail, although orthologues of the cheX gene are currently found in more than 20 sequenced bacterial genomes (Park et al., 2004). CheC and CheX share a sequence signature which is present also in the flagellar switch protein FliY from both organisms and, consequently, FliY was also demonstrated to act as a phosphatase on CheY $\sim \mathrm{P}$ (Szurmant et al., 2003). Therefore, the observation that $H$. pylori contains a CheY1 protein and the bifunctional CheAY2 histidine kinase suggested a similar mechanism of termination of chemotactic signalling as originally observed in the chemotaxis system of S. meliloti. This organism harbours two CheY molecules one of which interacts with the flagellar motor (CheY2) while the other acts as a phosphate sink (CheY1) which modulates the half-life of CheY2 $\sim \mathrm{P}$. This occurs via retro-transfer of the phosphoryl group from $\mathrm{CheY} 2 \sim \mathrm{P}$ to CheA and the subsequent CheA-dependent phosphorylation of CheY1 (Sourjik \& Schmitt, 1996; 1998). Our data presented here are consistent with efficient retro-transfer of the phosphoryl group from CheY1 P to CheAY2 and suggests a role of CheY2 as a phosphate sink involved in signal termination (Fig. 6a). In fact, in a three-component reaction where CheY1 is present predominantly in its phosphorylated form, while the P1 domain of $\mathrm{CheA}^{\prime}$ is initially unphosphorylated, the phosphotransfer from $\mathrm{CheA}^{\prime} \sim \mathrm{P}$ is clearly biased towards $\mathrm{CheY} 2$ despite the 

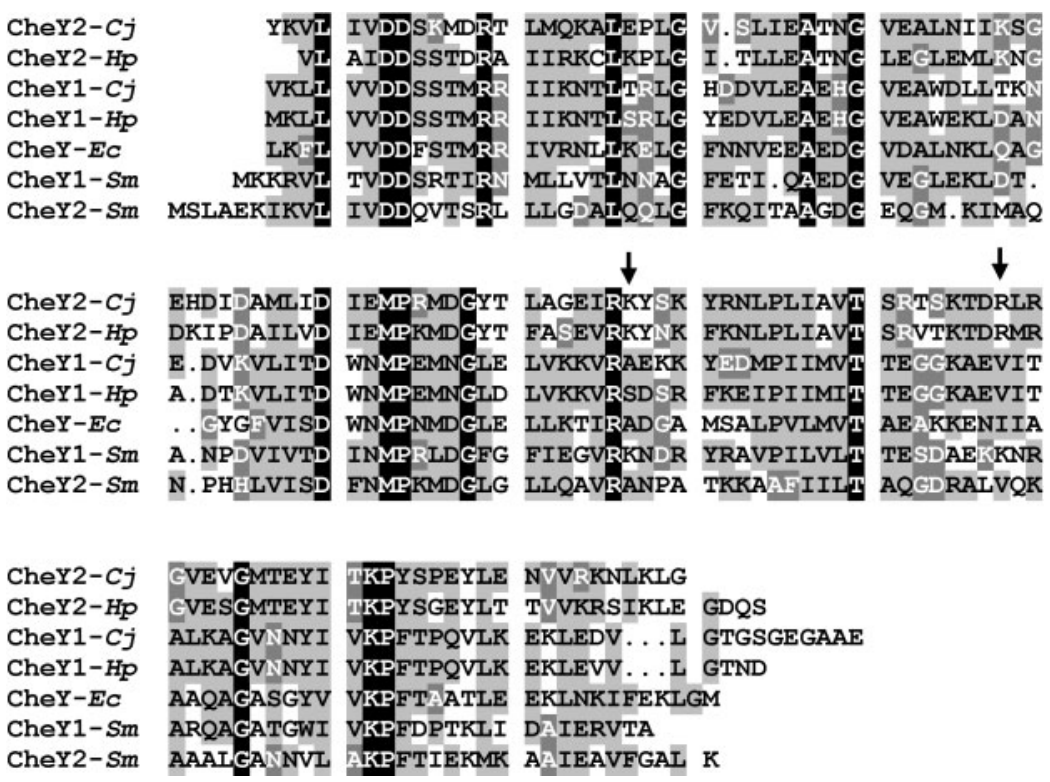

Fig. 7. Alignment of the amino acid sequences of the CheY proteins of $H$. pylori $(H p)$, C. jejuni $(C j)$, E. coli $(E C)$ and S. meliloti $(\mathrm{Sm})$. Gaps introduced to maximize the alignments are indicated by dots. The similarity between the homologous proteins is highlighted by different shading: black, all amino acids in a column are identical; light grey, more than half of the amino acids in a column are identical or belong to a strong similarity group; dark grey, more than half of the amino acids in a column belong to a weak similarity group or the amino acid marked in dark grey could be grouped into a weak similarity group with every amino acid of the same column belonging to a strong similarity group marked in light grey. Positions which are different in the CheY proteins interacting with the flagellar motor and acting as phosphate sink, respectively, are marked by arrows. higher affinity of CheY1 for CheA (Fig. $6 \mathrm{~b}$ and c). From the fact that in the retrophosphorylation experiments we could only detect $\mathrm{CheAY} 2 \sim \mathrm{P}$, but not $\mathrm{CheA}^{\prime} \sim \mathrm{P}$, we conclude that the phosphorylation signal generated by CheAY2 derives mainly from the phosphorylated Cterminal CheY2 domain and not from the P1 domain. This observation further supports the idea of a rapid flow of the phosphoryl group from CheY $1 \sim \mathrm{P}$ to $\mathrm{CheY} 2$ via the $\mathrm{P} 1$ domain of the CheA histidine kinase. Interestingly, an alignment of the CheY proteins of E. coli, S. meliloti, $H$. pylori and $C$. jejuni revealed two positions which might discriminate the CheY proteins interacting with the flagellar motor (CheY-Ec; CheY2-Sm; CheY1-Hp; CheY1-Cj) from those acting as a phosphate sink (CheY1-Sm; CheY2-Hp; CheY2-Cj): at the position corresponding to A74 in CheY of $E$. coli there is lysine in the 'phosphate sink' proteins and the position corresponding to $\mathrm{I} 95$ of E. coli CheY (V in CheY1-Hp and CheY2-Sm) is substituted by lysine or arginine in the 'phosphate sink' proteins (Fig. 7). However, these amino acids are probably not involved in the interaction with the FliM protein (McEvoy et al., 1999; Shukla et al., 1998).

H. pylori contains three orthologues of the chemotaxis protein $\mathrm{CheV}$, consisting of an $\mathrm{N}$-terminal CheW-like domain and a C-terminal receiver domain. CheV was first described in B. subtilis (Fredrick \& Helmann, 1994) and it was shown that phosphorylated $\mathrm{CheV}$ is involved in the adaptation to attractants (Karatan et al., 2001). To date only one of these proteins in $H$. pylori, $\mathrm{CheV1}$, has been shown to be required for normal chemotactic motility in swarming assays (Pittman et al., 2001). In accordance with the observation that binding of acetyl phosphate to $\mathrm{CheV} 2$ was detected by fluorescence spectroscopy (Pittman et al., 2001), we could directly show the phosphorylation of $\mathrm{CheV} 2$ in the presence of ${ }^{32} \mathrm{P}$-labelled acetyl phosphate. Here we show that the
CheV proteins are able to dephosphorylate $\mathrm{CheA}^{\prime}$, indicating the transfer of the phosphoryl group to the C-terminal receiver domain of the $\mathrm{CheV}$ proteins. Therefore, it is likely that the function of the CheV proteins is connected to their ability to be phosphorylated. Due to the low affinity of the $\mathrm{CheV}$ proteins for the CheA histidine kinase a role of the CheV proteins as a phosphate sink in terminating the chemotactic signalling seems rather unlikely.

We cannot, however, rule out the possibility that in $H$. pylori chemotaxis, a so far unknown CheY1 P- or CheY2 $\mathrm{P}$-specific phosphatase is involved in signal termination. Furthermore, the apparent slow half-life of CheY $2 \sim \mathrm{P}$ which, according to our results should act as a 'phosphate sink', may suggest that there could be a phosphatase specific for this response regulator. $H$. pylori contains an orthologue of FliY; however, the sequence similarity to the regions conserved between FliY, CheC and CheX from B. subtilis and T. maritima which act in $\mathrm{CheY} \sim \mathrm{P}$ hydrolysis is rather low.

Following the S. meliloti model, the CheY1 protein of $H$. pylori, which is freely diffusible in the cell, would interact with the flagellar motor. It was shown that the MCPs together with CheW and CheA form higher order clusters which are localized at the cell pole in E. coli and Rhodobacter sphaeroides (Maddock \& Shapiro, 1993; Sourjik \& Berg, 2000; Martin et al., 2003; Wadhams et al., 2000). In swarmer cells of Caulobacter crescentus the chemoreceptor McpA has been demonstrated to be localized to the flagellated cell pole (Alley et al., 1992). Assuming a similar localization of the chemoreceptor complex in the monotrichously flagellated bacterium $H$. pylori, direct interaction of CheAY2 with the flagellar motor is conceivable, but seems unlikely due to the complex stoichiometry of the MCP-CheW-CheA complexes which is a prerequisite for proper signal amplification (Levit et al., 2002; Shimizu et al., 2000). 
Computerized tracking of the movement of the $H$. pylori strain N6 revealed a swimming pattern consisting of short straight runs with frequent changes of direction, whereas mutants of $H$. pylori N6 with inactivated histidine kinase CheAY2 moved in long straight runs (Foynes et al., 2000), suggesting that phosphorylation of CheAY2 induces tumbling. Furthermore, in these assays a mutant with an insertional inactivation of cheY1 exhibited excessive tumbling. This observation is not consistent with the putative interaction of CheY1 with the flagellar motor proposed by our data, but would rather suggest a role of CheY1 in the termination of chemotactic signalling. For the moment, this apparent contradiction remains unexplained.

In conclusion, through reconstitution of the $H$. pylori chemotaxis proteins implicated in the signalling pathway, we have evidence of a complex phosphorelay in vitro which has similarities to other systems with multiple $\mathrm{CheY}$ proteins. The data presented here indicate that the receiver domain present in the bifunctional CheAY2 protein acts as a phosphate sink, fine tuning the activity of the freely diffusible CheY1 protein which is thought to interact with the flagellar motor. The role of the $\mathrm{CheV}$ proteins remains unclear at the moment, but they may be engaged in a further fine regulation of the phosphate flow in this complex chemotaxis system.

\section{ACKNOWLEDGEMENTS}

We thank Roy Gross for helpful discussions and critical reading of the manuscript. Birgit Scharf is acknowledged for helpful advice on the in vitro phosphorylation experiments. Birgit Scharf and Victor Sourjik are acknowledged for kindly providing plasmid pVS69 expressing $\mathrm{CheY}$ from E. coli with a C-terminal $\mathrm{His}_{6}$-tag. This work was supported by a grant from the Deutsche Forschungsgemeinschaft (BE 1543/4-1).

\section{REFERENCES}

Alley, M. R. K., Maddock, J. R. \& Shapiro, L. (1992). Polar localization of a bacterial chemoreceptor. Genes Dev 6, 825-836.

Alm, R. A., Ling, L.-S. L., Moir, D. T. \& 20 other authors (1999). Genomic-sequence comparison of two unrelated isolates of the human gastric pathogen Helicobacter pylori. Nature 397, 176-180.

Baar, C., Eppinger, M., Raddatz, G. \& 12 other authors (2003). Complete genome sequence and analysis of Wolinella succinogenes. Proc Natl Acad Sci U S A 100, 11690-11695.

Beier, D. \& Frank, R. (2000). Molecular characterization of twocomponent systems of Helicobacter pylori. J Bacteriol 182, 2068-2076.

Beier, D., Spohn, G., Rappuoli, R. \& Scarlato, V. (1997). Identification and characterization of an operon of Helicobacter pylori that is involved in motility and stress adaptation. J Bacteriol 179, 4676-4683.

Blaser, M. J. (1992). Helicobacter pylori: its role in disease. Clin Infect Dis 5, 386-391.

Bourret, R. B., Hess, J. F. \& Simon, M. I. (1990). Conserved aspartate residues and phosphorylation in signal transduction by the chemotaxis protein CheY. Proc Natl Acad Sci U S A 87, 41-45.
Cerda, O., Rivas, A. \& Toledo, H. (2003). Helicobacter pylori strain ATCC 700392 encodes a methyl-accepting chemotaxis receptor protein (MCP) for arginine and sodium bicarbonate. FEMS Microbiol Lett 224, 175-181.

Eaton, K. A., Morgan, R. R. \& Krakowka, S. (1992). Motility as a factor in the colonization of gnotobiotic piglets by Helicobacter pylori. J Med Microbiol 37, 123-127.

Eaton, K. A., Suerbaum, S., Josenhans, C. \& Krakowka, S. (1996). Colonization of gnotobiotic piglets by Helicobacter pylori deficient in two flagellin genes. Infect Immun 64, 24452448.

Foynes, S., Dorrell, N., Ward, S. J., Stabler, R. A., McColm, A. A., Rycroft, A. N. \& Wren, B. W. (2000). Helicobacter pylori possesses two CheY response regulators and a histidine kinase sensor, CheA, which are essential for chemotaxis and colonization of the gastric mucosa. Infect Immun 68, 2016-2023.

Fredrick, K. L. \& Helmann, J. D. (1994). Dual chemotaxis signaling pathways in Bacillus subtilis: a sigma D-dependent gene encodes a novel protein with both $\mathrm{CheW}$ and CheY homologous domains. J Bacteriol 176, 2727-2735.

Georgellis, G., Lynch, A. S. \& Lin, E. C. C. (1997). In vitro phosphorylation study of the Arc two-component signal transduction system of Escherichia coli. J Bacteriol 179, 5429-5435.

Karatan, E., Saulmon, M. M., Bunn, M. W. \& Ordal, G. W. (2001). Phosphorylation of the response regulator $\mathrm{CheV}$ is required for adaptation to attractants during Bacillus subtilis chemotaxis. J Biol Chem 276, 43618-43626.

Levit, M. N., Grebe, T. W. \& Stock, J. B. (2002). Organization of the receptor-kinase signalling array that regulates Escherichia coli chemotaxis. J Biol Chem 277, 36748-36754.

Lukat, G. S., Lee, B. H., Mottonen, J. M., Stock, A. M. \& Stock, J. B. (1991). Roles of the highly conserved aspartate and lysine residues in the response regulator of bacterial chemotaxis. J Biol Chem 266, 8348-8354

Lukat, G. S., McCleary, W. R., Stock, A. M. \& Stock, J. B. (1992). Phosphorylation of bacterial response regulator proteins by low molecular weight phospho-donors. Proc Natl Acad Sci U S A 89, 718-722.

Maddock, J. R. \& Shapiro, L. (1993). Polar location of the chemoreceptor complex in the Escherichia coli cell. Science 259, 1717-1723.

Martin, A. C., Nair, U., Armitage, J. P. \& Maddock, J. R. (2003). Polar localization of CheA2 in Rhodobacter sphaeroides requires specific Che homologs. J Bacteriol 185, 4667-4671.

McCleary, W. R. \& Stock, J. B. (1994). Acetyl phosphate and the activation of two-component response regulators. J Biol Chem 269, 31567-31572.

McEvoy, M. M., Bren, A., Eisenbach, M. \& Dahlquist, F. W. (1999). Identification of the binding interfaces on CheY for two of its targets, the phosphatase CheZ and the flagellar switch protein FliM. J Mol Biol 289, 1423-1433.

McGee, D. J., Langford, M. L., Watson, E. L., Carter, J. E., Chen, Y.-T. \& Ottemann, K. M. (2005). Colonization and inflammation deficiencies in mongolian gerbils infected by Helicobacter pylori chemotaxis mutants. Infect Immun 73, 1820-1827.

Ottemann, K. M. \& Lowenthal, A. (2002). Helicobacter pylori uses motility for both initial colonization and to attain robust infection. Infect Immun 70, 1984-1990.

Park, S.-Y., Chao, X., Gonzalez-Bonet, G., Beel, B. D., Bilwes, A. M. $\&$ Crane, B. R. (2004). Structure and function of an unusual family of protein phosphatases: the bacterial chemotaxis proteins $\mathrm{CheC}$ and CheX. Mol Cell 16, 563-574. 
Parkhill, J., Wren, B. W., Mungall, K. \& 18 other authors (2000). The genome sequence of the food-borne pathogen Campylobacter jejuni reveals hypervariable sequences. Nature 403, 665-668.

Perraud, A.-L., Kimmel, B., Weiss, V. \& Gross, R. (1998). Specificity of the BvgAS and EvgAS phosphorelay is mediated by the C-terminal HPt domains of the sensor proteins. Mol Microbiol 27, 875-887.

Peterson, W. L. (1991). Helicobacter pylori and peptic ulcer disease. $N$ Engl J Med 324, 1043-1048.

Pittman, M. S., Goodwin, M. \& Kelly, D. J. (2001). Chemotaxis in the human gastric pathogen Helicobacter pylori: different roles for CheW and the three $\mathrm{CheV}$ paralogues, and evidence for $\mathrm{CheV} 2$ phosphorylation. Microbiology 147, 2493-2504.

Schmitt, R. (2002). Sinorhizobial chemotaxis: a departure from the enterobacterial paradigm. Microbiology 148, 627-631.

Shimizu, T. S., Le Novere, N., Levin, M. D., Beavil, A. J., Sutton, B. J. \& Bray, D. (2000). Molecular model of a lattice of signalling proteins involved in bacterial chemotaxis. Nature Cell Biol 2 792-796.

Shukla, D., Zhu, X. Y. \& Matsumura, P. (1998). Flagellar motorswitch binding face of Chey and the biochemical basis of suppression by CheY mutants that compensate for motor-switch defects in Escherichia coli. J Biol Chem 273, 23993-23999.

Sourjik, V. \& Berg, H. C. (2000). Localization of the components of the chemotaxis machinery of Escherichia coli using fluorescent protein fusions. Mol Microbiol 37, 740-751.

Sourjik, V. \& Schmitt, R. (1996). Different roles of CheY1 and CheY2 in the chemotaxis of Rhizobium meliloti. Mol Microbiol 22, 427-436.

Sourjik, V. \& Schmitt, R. (1998). Phosphotransfer between CheA, CheY1, and CheY2 in the chemotaxis signal transduction chain of Rhizobium meliloti. Biochemistry 37, 2327-2335.

Suerbaum, S., Josenhans, C., Sterzenbach, T. \& 19 other authors (2003). The complete genome sequence of the carcinogenic bacterium Helicobacter hepaticus. Proc Natl Acad Sci U S A 100, 7901-7906.
Szurmant, H. \& Ordal, G. W. (2004). Diversity in chemotaxis mechanisms among the bacteria and archaea. Microbiol Mol Biol Rev 68, 301-319.

Szurmant, H., Bunn, M. W., Cannistraro, V. J. \& Ordal, G. W. (2003). Bacillus subtilis hydrolyzes CheY-P at the location of its action, the flagellar switch. J Biol Chem 278, 48611-48616.

Szurmant, H., Muff, T. J. \& Ordal, G. W. (2004). Bacillus subtilis CheC and FliY are members of a novel class of $\mathrm{CheY} \sim \mathrm{P}$-hydrolyzing proteins in the chemotactic signal transduction cascade. J Biol Chem 279, 21787-21792.

Terry, K., Williams, S. M., Connolly, L. \& Ottemann, K. M. (2005). Chemotaxis plays multiple roles during Helicobacter pylori animal infection. Infect Immun 73, 803-811.

Tomb, J.-F., White, O., Kerlavage, A. R. \& 39 other authors (1997). The complete genome sequence of the gastric pathogen Helicobacter pylori. Nature 388, 539-547.

Uemura, N. S., Okamoto, S., Yamamoto, S., Matsumura, N., Yamaguchi, S., Yamakido, M., Taniyama, K., Sasaki, N. \& Schlemper, R. J. (2001). Helicobacter pylori infection and the development of gastric cancer. $N$ Engl J Med 345, 784-789.

Wadhams, G. H. \& Armitage, J. P. (2004). Making sense of it all: bacterial chemotaxis. Nat Rev Mol Cell Biol 5, 1024-1037.

Wadhams, G. H., Martin, A. C. \& Armitage, J. P. (2000). Identification and localization of a methyl-accepting chemotaxis protein in Rhodobacter sphaeroides. Mol Microbiol 36, 1222-1233.

Worku, M. L., Karim, Q. N., Spencer, J. \& Sidebotham, R. L. (2004). Chemotactic response of Helicobacter pylori to human plasma and bile. J Med Microbiol 53, 807-811.

Xiang, Z., Censini, S., Bayeli, P. F., Telford, J. L., Figura, N., Rappuoli, R. \& Covacci, A. (1995). Analysis of expression of CagA and VacA virulence factors in 43 strains of Helicobacter pylori reveals that clinical isolates can be divided into two major types and that CagA is not necessary for expression of the vacuolating cytotoxin. Infect Immun 63, 94-98.

Yoshiyama, H., Nakamura, H., Kimoto, M., Okita, K. \& Nakazawa, T. (1999). Chemotaxis and motility of Helicobacter pylori in a viscous environment. J Gastroenterol 34, 18-23. 